\title{
SMOKERS WITH INTRACRANIAL ANEURYSMS WHO UNDERWENT NEUROSURGICAL OR ENDOVASCULAR TREATMENT HAVE NOT STOPPED SMOKING ONE YEAR AFTER SURGERY
}

\author{
Kamila Zvolská', , Eva Králíková', 2 , Vladimír Beneš3, Jana Koblihová4, Jiří Rameš1, David Netuka3 \\ ${ }^{1}$ Institute of Hygiene and Epidemiology, First Faculty of Medicine, Charles University in Prague and General University Hospital in Prague, \\ Czech Republic \\ 23rd Department of Medicine - Department of Endocrinology and Metabolism, First Faculty of Medicine, Charles University in Prague and \\ General University Hospital in Prague, Czech Republic \\ ${ }^{3}$ Department of Neurosurgery, First Faculty of Medicine, Charles University in Prague and Central Military Hospital, Prague, Czech Republic \\ ${ }^{4}$ Department of Clinical Psychology, Central Military Hospital, Prague, Czech Republic
}

\begin{abstract}
SUMMARY
Smoking increases the risk of forming, growing, and rupture of intracranial aneurysms. We retrospectively reviewed patients with intracranial aneurysms treated by neurosurgical or endovascular treatment -154 patients ( 45 men, 109 women, 15 to 62 years, average 46.3 years, $\mathrm{Cl} \pm 1.72$ ). We found $74 \%$ (114/154) of smokers - 80\% (36/45) men and 71.6\% (78/109) women, with the mean value of the Fagerström Test of Nicotine Dependence $4.4(\mathrm{Cl} \pm 0.40)$. The average age of smoking initiation was 18.2 years $(\mathrm{Cl} \pm 0.66)$, the average period of smoking 26.8 years ( $\mathrm{Cl} \pm 2.13)$. The average number of cigarettes consumed daily was $18.2(\mathrm{Cl} \pm 1.58)$. With statistical significance $\mathrm{p}<0.05$, the athero-index was lower in nonsmokers than smokers: $3.4(\mathrm{Cl} \pm 0.56)$ vs. $4.5(\mathrm{Cl} \pm 0.51)$. $\mathrm{HDL}$ cholesterol was higher in non-smokers than smokers: $1.6 \mathrm{mmol} / \mathrm{l}(\mathrm{Cl} \pm 0.25)$ vs. 1.4 $(\mathrm{Cl} \pm 0.10)$, and triglycerides were higher in smokers than non-smokers: $1.3 \mathrm{mmol} / \mathrm{l}(\mathrm{Cl} \pm 0.16)$ vs. $1.9(\mathrm{Cl} \pm 0.35)$. Forty-two per cent of smokers (48/114) were controlled one year after the treatment; $18.8 \%$ of them stopped smoking, $41.7 \%$ reduced smoking, and $39.6 \%$ continued to smoke as extensively as before. The prevalence of smoking in our sample was higher than in the Czech population (28.2\%). Only $18.8 \%$ of controlled smokers were able to quit one year after the intervention.
\end{abstract}

Key words: smoking, smoking cessation, intracranial aneurysm, subarachnoid hemorrhage, Fagerström Test for Nicotine Dependence

Address for correspondence: K. Zvolská, General University Hospital in Prague, Tobacco Dependence Treatment Centre, Karlovo náměstí 32, 12800 Praha 2, Czech Republic. E-mail: kzvolska@centrum.cz

\section{INTRODUCTION}

An intracranial aneurysm (IA) is a thin walled outpouching or dilatation of the brain artery. It originates in local infliction of the vascular wall by atherosclerosis, trauma, infection (mycotic aneurysms resulting from infected embolic material from a bacterial infection on one of the heart valves), neoplastic disease, and most often by congenital abnormality of the intima with abnormal thinning of the artery (1-3).

Many studies imply that smoking is a very important risk factor in the formation of intracranial aneurysms, with OR from 1.7 to 3.48 (4-6) (Table 1). Smoking and possibly also age and female sex seem to be risk factors for multiple intracranial aneurysms (OR of smoking $2.10 ; 95 \% \mathrm{CI}, 1.06-4.13)$ (7). Cigarette smoking appears to increase the risk for growth of larger aneurysms (see e.g. the studies of The Department of Neurosurgery, University at Buffalo and University of Colorado in Denver). Smoking (OR 2.2; 95\% CI, 1.1-4.5) and middle cerebral artery origin (OR $2.5 ; 95 \% \mathrm{CI}, 1.3-4.9$ ) seem to increase the risk of developing large aneurysms (6).
Smoking has also been proved to increase the risk of IA rupture (OR from 2.2 to 4.1 for former smokers, 5.4 for current smokers, respectively) that leads to subarachnoid hemorrhage (SAH) $(6,8,9$, 10) (Table 1). Hypotheses explaining the effects of smoking on IA rupture include enhanced systematic coagulability, inflammation within arterial walls, increased blood pressure, endothelial dysfunction, and the promotion of degradation of elastin within vessel walls by interfering with alfal-antitrypsin $(6,11)$. Arterial hypertension is also a significant independent risk factor for aneurysmal SAH, OR from 2.4 to $6.8(8,9,10,12)$ (Table 1$)$.

With regard to the minimal symptomatology of intracranial aneurysms, it is very important to support a healthy life style involving non-smoking. Cigarette smoking is the most important preventable cause of SAH, with a strong dose-response relationship having been shown in many studies. After smoking cessation the risk of aneurysmal rupture declines (11).

In the Czech Republic, with 10,429,692 inhabitants (13), the prevalence of smoking is $28.2 \%$ in the population older than 15 years (30.3\% in men and $25.9 \%$ in women) (14). 
Table 1. Smoking and hypertension as risk factors for intracranial aneurysms and aneurysmal SAH

\begin{tabular}{|l|c|c|c|}
\hline \multirow{2}{*}{} & \multicolumn{2}{|c|}{ OR } \\
\cline { 2 - 4 } & of smoking for intracranial aneurysm & of smoking for aneurysmal SAH & of hypertension for aneurysmal SAH \\
\hline Matsumoto et al., 1999 & 1.7 & & \\
\hline Qureshi et al., 2000 & 2.2 & & \\
\hline Juvela, 2002 & $95 \%$ Cl 1.1-4.5 & & 2.4 \\
\hline Qureshi et al., 2001 & 3.48 & & $95 \% \mathrm{Cl} 1.8-3.1$ \\
\hline Kubota et al., 2001 & $95 \% \mathrm{Cl} 1.14-10.64$ & 5.4 & 2.65 \\
\hline Isaksen et al., 2002 & & $95 \% \mathrm{Cl} 3.7-7.8$ & 2.46 \\
\hline Kleinpeter and Lehr, 2002 & & 2.54 & $95 \% \mathrm{Cl} 1.52-3.97$ \\
\hline
\end{tabular}

This study does not seek to prove that smoking causes intracranial aneurysms. It addresses the resistance of our study sample to smoking cessation. We wanted to assess a sample of patients with diagnoses of intracranial aneurysms, find out the prevalence of smoking among these patients, and check their smoking status after one year.

\section{METHODS}

We retrospectively reviewed patients who had undergone the neurosurgical or endovascular treatment of intracranial aneurysms. The patients were informed about the impact of smoking on their disease and motivated to stop smoking (short intervention cca 10 minutes). We contacted all our patients one year after the neurosurgical or endovascular intervention to determine smoking status of those agreeable with follow-up examination.

The sample studied consists of patients with ruptured and unruptured intracranial aneurysms (IA) treated by neurosurgical or endovascular treatment at the Department of Neurosurgery of the Central Military Hospital, Prague, between January 2000 and December 2003.

A studied group consisted of 154 patients (45 men, 109 women, between the ages of 15 and 62) with the average age of the whole sample being 46.3 years (SD 10.8). Smoking status was determined by use of a questionnaire. "Smoker" was in our case everyone who, at the time of the study, smoked daily. Non-smokers included never-smokers and former smokers (exsmokers for more than a year). There were not any occasional smokers in our sample. Patients were informed about the health hazards posed by smoking in respect of their disease; no other intervention was provided.

We also examined blood pressure and blood lipids such as total cholesterol (TC), triglycerides, HDL cholesterol, LDL cholesterol and athero-index (TC to HDL cholesterol ratio). Blood lipids were examined one year after the intervention. Statistical significance for the presented values was calculated by Independent Samples t-test.

Smoking status was checked up one year after the neurosurgical intervention in those patients who came for a follow-up examina- tion. They answered the questions: "Do you smoke as extensively as a year ago?; Have you reduced your smoking ( $50 \%$ and fewer cigarettes daily compared to a year before)?; Did you stop smoking?"

\section{RESULTS}

Among our patients, 74\% (114/154) were smokers - 80\% (36/45) in men and $71.6 \%$ in women (78/109) (Fig. 1) were heavily nicotine dependent with a Fagerström Test for Nicotine Dependence (FTND) mean score of 4.4 (SD 1.94). All of them smoked daily and there was no occasional smoker among them. Their average age of initiation of regular smoking was 18.2 years (SD 3.40) and the average period of smoking was 26.8 years (SD 11.06). The average number of cigarettes smoked daily was 18.2 (SD 8.42). Smokers tend to have lower education compared to non-smokers $-15 \%$ of non-smokers had university education (11.11\% men, $16.13 \%$ women) as opposed to $8.77 \%$ of smokers ( $13.89 \%$ men, $6.41 \%$ women).

There was a 2.85 times higher number of smokers than nonsmokers in our sample -4 times higher a number of smokers than non-smokers among men and 2.52 times higher a number of women smokers than non-smokers.

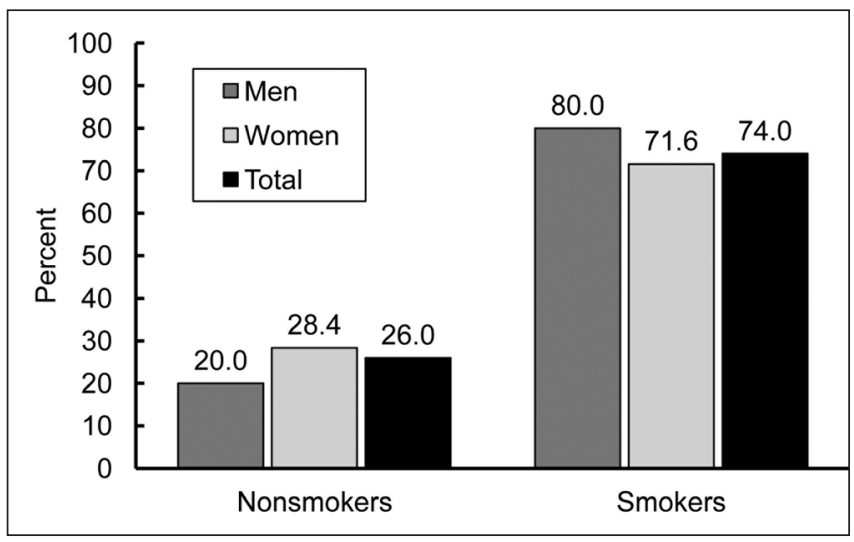

Fig. 1. Smoking status among patients. 
Other risk factors for atherosclerosis in smokers and nonsmokers were evaluated. For the whole sample total cholesterol, LDL cholesterol, and elevated blood pressure were positively associated with smoking, but without any statistical significance.

With statistical significance of $\mathrm{p}<0.05$, the athero-index (TC/ HDL) was lower in non-smokers than in smokers: $3.4(\mathrm{CI} \pm 0.56)$ vs. $4.5(\mathrm{CI} \pm 0.51)$, HDL cholesterol was higher in non-smokers than smokers: $1.6 \mathrm{mmol} / 1(\mathrm{CI} \pm 0.25)$ vs. $1.4(\mathrm{CI} \pm 0.10)$, and triglycerides were higher in smokers than in non-smokers: 1.9 $(\mathrm{CI} \pm 0.35)$ vs. $1.3 \mathrm{mmol} / 1$ (CI \pm 0.16$)$ (Fig. 3 ).

Forty-two per cent of smokers (48/114) were seen again one year after neurosurgical or endovascular treatment; $18.8 \%$ of them had stopped smoking (9/48), 41.7\% (20/48) had reduced smoking (smoked daily at least $50 \%$ fewer cigarettes compared to a year before), and $39.6 \%(19 / 48)$ smoked the same amount of cigarettes as a year before (Fig. 2).

\section{DISCUSSION}

From the literature it is evident that cigarette smoking is a risk factor responsible for forming, growing, and rupture of intracranial aneurysms $(4-6,8-10,12)$.

The prevalence of smoking in our sample was much higher compared to $28.2 \%$ prevalence found out in the Czech general population. It is alarming because IA severe enough to be treated by neurosurgical intervention is a very serious diagnosis. It could reflect the fact that many people don't realize the relationship between their diagnosis and cigarette smoking. The prevalence of smoking was determined from questionnaires. We could assume higher prevalence of smoking in the study sample in case of measuring expired air carbon monoxide.

Blood lipids were examined one year after the intervention. Their level may be influenced also by age, diet, and BMI.

Less than one third of the sample were men (29.2\%). It would be interesting to compare a group of men and a group of women in the future phase of this study which is still continuing in order to test the role of sex in the formation of multiple intracranial aneurysms that has been suggested in some publications (7) as well as to explore the relationship between smoking and type, location, etc., of IA.

The average age of smokers was 47.3 years (SD 10.4) vs. years 43.4 in non-smokers (SD 11.6).

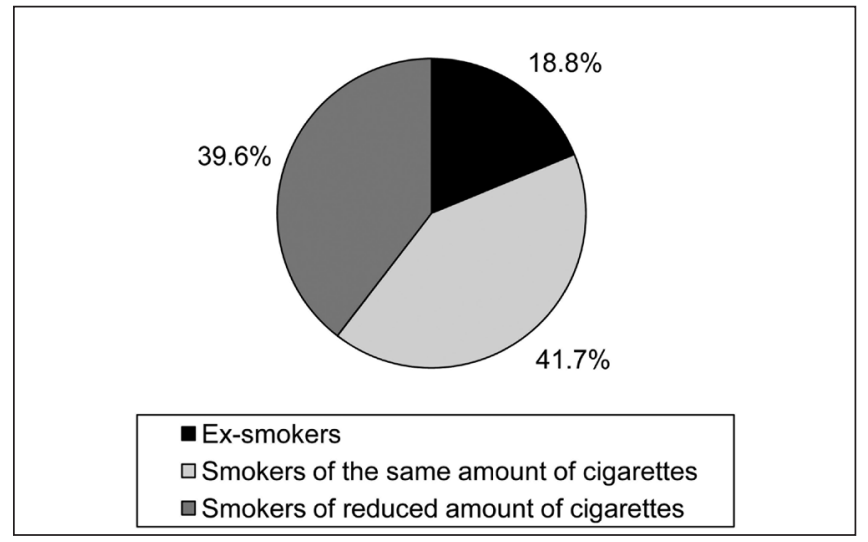

Fig. 2. Smoking status after one year.

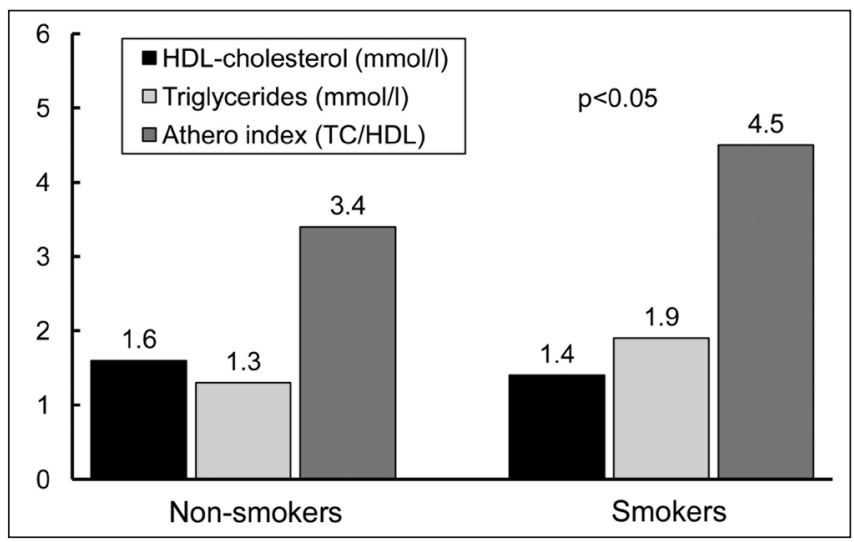

Fig. 3. Blood lipids and smoking status.

The study's smokers were heavily nicotine dependent regular, daily smokers, with a mean FTND of 4.4 (SD 1.94). They smoked average 18.2 (SD 8.42) cigarettes daily. The likelihood of a successful quit attempt without professional help is very low for nicotine dependent smokers. The quitting success rate in the general population with good tobacco control is only about $2 \%$ per year (15). It was 7.9\% (9/114) in our sample, but if determined by measuring expired air carbon monoxide, the success rate could be lower. Fifty-eight per cent of smokers had lost to follow-up $(66 / 114)$, so they were considered to be smokers.

\section{CONCLUSIONS}

Despite the short intervention and knowledge of highly risky behaviour, only $18.8 \%$ of smokers $(7.9 \%$ of the sample) were able to quit smoking one year after treatment of the intracranial aneurysm. This demonstrates the resistance of the study sample to smoking cessation. Patients with known intracranial aneurysms should definitely stop smoking. Intensive treatment of tobacco dependence should be actively offered to this high risk group. The study still continues.

\section{Acknowledgements:}

Supported by GACR no. 313/95/1084 and IGA MZ CR 9640-4.

\section{Competing Interests:}

None declared.

\section{REFERENCES}

1. Mumenthaler M, Mattle H. Disturbances of cerebral perfusion and nontraumatic intracranial hemorrhage. In: Neurologie. Prague: Grada; 2001. p. 192-200. (In Czech.)

2. Plas J, Kozler P, Kroo M, Malec R, Parizek J, Travnicek V. Aneurysmal subarachnoid hemorrhage. In: Neurochirurgie. Prague: Galen; 2000. p. 58-60. (In Czech.)

3. Nevsimalova S, Ruzicka E, Tichy J, Bauer J, Böhm J, Docekal P, et al. Vascular diseases of the brain. In: Neurologie. Prague: Galen; 2002. p. 171-75. (In Czech.)

4. Juvela S. Natural history of unruptured intracranial aneurysms: risks for aneurysm formation, growth, and rupture. Acta Neurochir Suppl. 2002;82:27-30. 
5. Matsumoto K, Akagi K, Abekura M, Ohkawa M, Tasaki O, Oshino S. Cigarette smoking increases the risk of developing a cerebral aneurysm and of subarachnoid hemorrhage. No Shinkei Geka. 1999 Sep;27(9):8315. (In Japanese.)

6. Qureshi AI, Sung GY, Suri MF, Straw RN, Guterman LR, Hopkins LN. Factors associated with aneurysm size in patients with subarachnoid hemorrhage: effect of smoking and aneurysm location. Neurosurgery. 2000 Jan;46(1):44-50

7. Juvela S. Risk factors for multiple intracranial aneurysms. Stroke. 2000 Feb;31(2):392-7.

8. Isaksen J, Egge A, Waterloo K, Romner B, Ingebrigtsen T. Risk factors for aneurysmal subarachnoid haemorrhage: the Tromso study. J Neurol Neurosurg Psychiatry. 2002 Aug;73(2):185-7.

9. Kleinpeter $\mathrm{G}, \mathrm{Lehr} \mathrm{S}$. Is hypertension a major risk factor in aneurysmal subarachnoid hemorrhage? Wien Klin Wochenschr. 2002 May 15;114(89):307-14.

10. Kubota M, Yamaura A, Ono J. Prevalence of risk factors for aneurysmal subarachnoid haemorrhage: results of a Japanese multicentre case control study for stroke. Br J Neurosurg. 2001 Dec;15(6):474-8.

11. Anderson CS, Feigin V, Bennett D, Lin RB, Hankey G, Jamrozik K; Australasian Cooperative Research on Subarachnoid Hemorrhage Study (ACROSS) Group. Active and passive smoking and the risk of subarach- noid hemorrhage: an international population-based case-control study. Stroke [Internet]. 2004 Mar [cited 2011 Jun 10];35(3):633-7. Available from: http://stroke.ahajournals.org/cgi/content/full/35/3/633.

12. Qureshi AI, Suri MF, Yahia AM, Suarez JI, Guterman LR, Hopkins LN, et al. Risk factors for subarachnoid hemorrhage. Neurosurgery. 2001 Sep;49(3):607-12; discussion 612-3.

13. Institute of Health Information and Statistics of the Czech Republic. Czech Republic: basic information [Internet]. Prague: IHIS CR; 2009 [cited 2009 Nov 19]. Available from: http://www.uzis.cz/en/cze-regions.

14. Sovinova H, Sadilek P, Csemy L. Progression of prevalence of smoking in adults in the Czech Republic, opinions of citizens to issues of smoking (1997-2008). Research report [Internet]. Prague: National Institute of Public Health; 2009 [cited 2009 Nov 19]. Available from: http://www.szu.cz/ uploads/documents/czzp/zavislosti/koureni/Koureni2008_DEF_feb010. pdf. (In Czech.)

15. Králíková E, Býma S, Cífková R, Ceska R, Dvorák V, Hamanová J, et al. Recommendations for the treatment of tobacco dependence. Cas Lek Cesk. 2005;144(5):327-33. (In Czech.)

Received February 22, 2011 Accepted in revised form June 30, 2011 